\title{
Encasement of the Left Internal Mammary Arterial Graft to the Left Coronary Artery by Adenosquamous Carcinoma, an Unusual Tumor
}

\author{
Pallavi Solanki ${ }^{1}$, Alfonso H. Waller ${ }^{1}$, Abbas Shehadeh ${ }^{1}$, Pierre D. Maldjian ${ }^{2}$, Edo Kaluski ${ }^{1}$, \\ Muhamed Saric ${ }^{1}$ and Yuliya Kats ${ }^{*}, 1$
}

Departments of ${ }^{1}$ Medicine, and ${ }^{2}$ Radiology, New Jersey Medical School, Newark, NJ, USA

\begin{abstract}
We report a case of a patient with a previous coronary artery bypass graft who presented with chest pain and was found to have adenosquamous carcinoma encasing the left internal mammary graft to left anterior descending artery the only viable vessel to his coronary circulation. Adenosquamous carcinoma, a rare lung cancer with a poor prognosis, causing obstruction of a bypass graft has not been previously reported.
\end{abstract}

Keywords: Echocardiography, adenosquamous carcinoma, coronary bypass surgery, left internal mammary artery.

\section{CASE REPORT}

A 77-year-old man was admitted to our telemetry unit with presumed acute coronary syndrome. Six years earlier he underwent off-pump coronary artery bypass surgery (CABG) consisting of a left internal mammary artery (LIMA) graft to the left anterior descending (LAD), and a reverse saphenous venous graft from the LIMA to the first obtuse marginal branch. He was a former smoker who quit 5 years earlier with a 25-pack-year smoking history. He was on appropriate medical therapy for his arterial hypertension, type II diabetes mellitus, hyperlipidemia, and ischemic cardiomyopathy with an ejection fraction of $20 \%$. The physical examination on admission was unremarkable.

Coronary angiography identified severe native coronary artery disease (100\% occlusion of mid LAD, $70-80 \%$ stenosis of proximal left circumflex branch, $80-95 \%$ stenosis of the first obtuse marginal, 96-99\% stenosis of the second obtuse marginal, and $100 \%$ occlusion of the proximal right coronary artery with its distal territory filling from the leftto-right collaterals). There was also complete occlusion of the saphenous venous graft. Several centimeters proximal to the anastomosis of LIMA to LAD, the LIMA graft had an unusual narrowing of its luminal diameter. By visual estimate there was a 70-80\% stenosis of a long segment in the mid portion of the LIMA (Fig. 1).

A chest computed tomography (CT) with contrast revealed a nonenhancing soft-tissue anterior mediastinal mass measuring $2.1 \times 3.6 \mathrm{~cm}$ and having irregular borders. The mass was encasing and partially obstructing the LIMA bypass graft, as well as the left subclavian vein and the innominate vein (Figs. 2, 3). A fluorine-18 fluorodeoxyglucose (FDG) positron emission tomography (PET) was then performed to further evaluate the mass. The scan revealed a 2.0 $x 3.5 \mathrm{~cm}$ soft tissue mass with intense uptake in the left

*Address correspondence to this author at the Echocardiography Laboratory, Division of Cardiovascular Diseases, New Jersey Medical School, 185 South Orange Avenue I-538, University Heights, Newark, NJ 07103, USA; Tel: (973) 972-6084; Fax: (973) 972-4737; E-mail: yuliya.kats@gmail.com

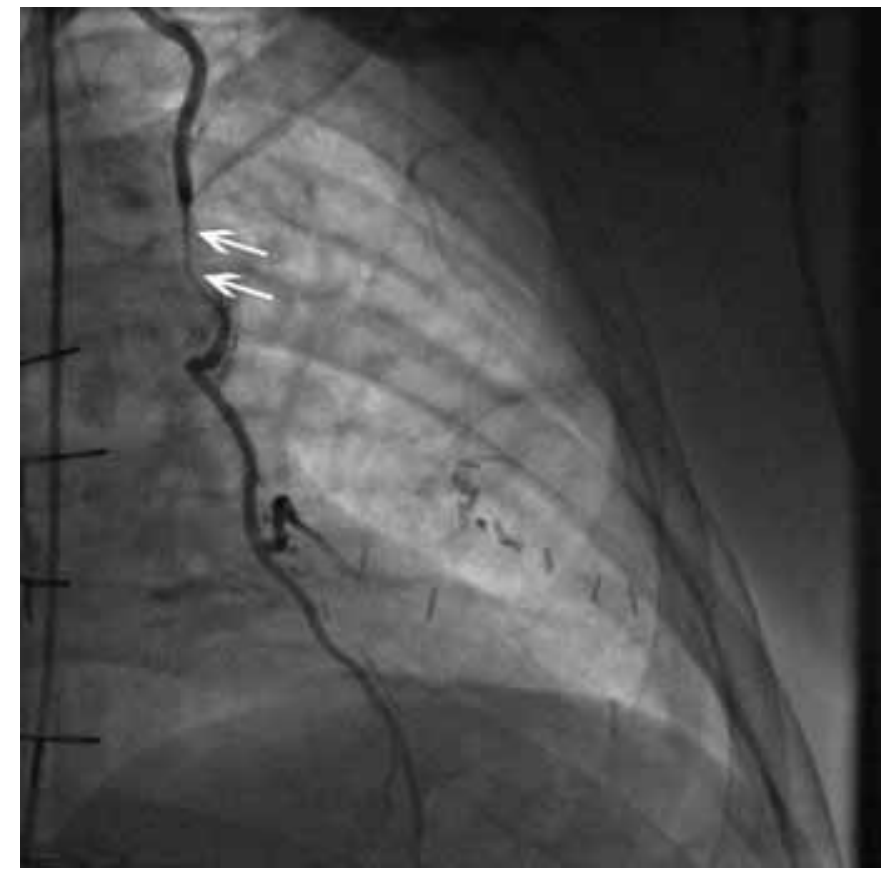

Fig. (1). Cardiac Catheterization. Selective injection of the left internal mammary graft in an anteroposterior view with an 18degree cranial angulation reveals a long segment of narrowing in the proximal portion of the internal mammary artery (arrows).

aspect of the anterior mediastinum, suspicious for a neoplasm (Fig. 4).

Cardiothoracic surgery at our institution and another tertiary medical center evaluated the patient for possible redo $\mathrm{CABG}$ and concomitant resection of the mass responsible for angina due to external compression of the LIMA. It was concluded that the surgical risks were prohibitive given the patient's co-morbidities. Instead, the patient underwent percutaneous coronary intervention with stenting of the LIMA graft.

A follow-up 16-slice CT angiography with 3D reconstruction revealed patency of the stented LIMA graft (Fig. 5). 


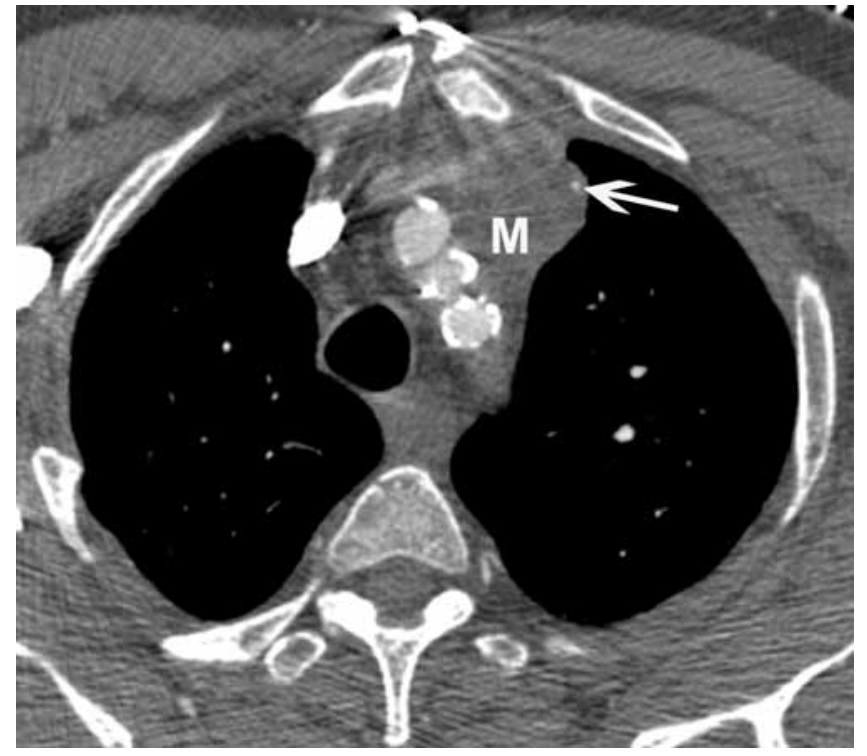

Fig. (2). Initial Chest CT. Axial computed tomography image reveals an anterior mediastinal mass (M) with encasement of the left internal mammary arterial graft in the anterior mediastinum (arrow).

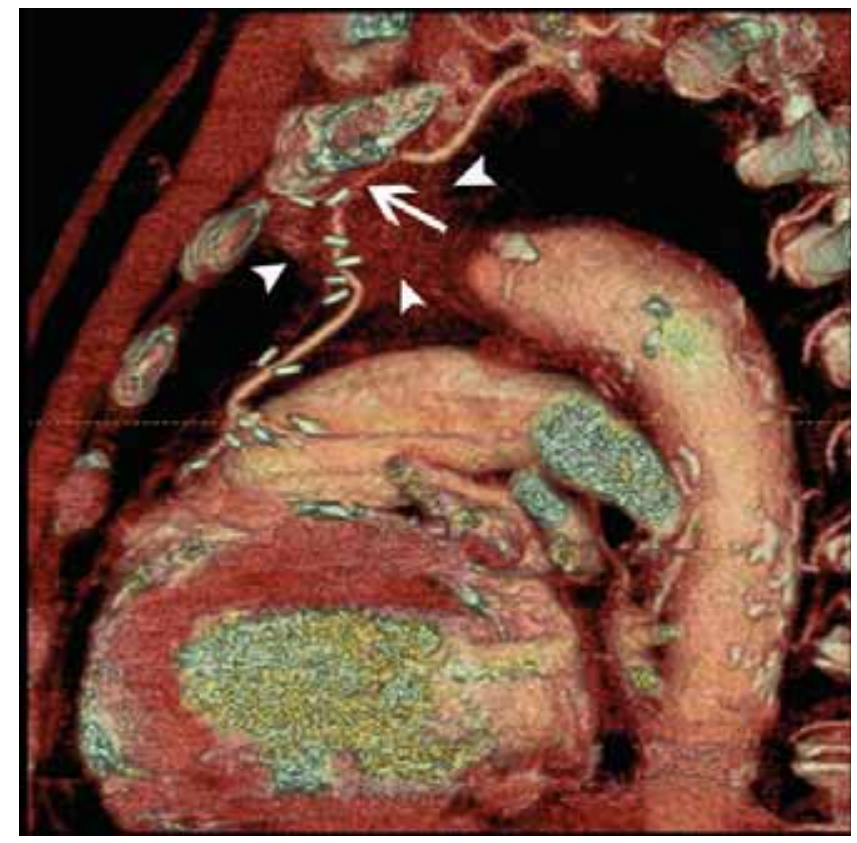

Fig. (3). 3D CT. Three-dimensional volume-rendered computed tomography image from left lateral perspective reveals an anterior mediastinal mass measuring $2.1 \times 3.6 \mathrm{~cm}$ with irregular borders. The mass (arrowheads) is encasing the left internal mammary artery bypass graft (arrow).

Surgical pathology of a CT-guided percutaneous biopsy of the anterior mediastinal mass revealed adenosquamous carcinoma, an uncommon tumor. It was subsequently determined to be stage IIIB. The patient was given palliative radiation therapy to the mediastinum and was discharged without symptoms.

\section{DISCUSSION}

Patients with lung cancer frequently have coexisting coronary artery disease since advanced age and smoking are common risk factors. Concomitant coronary revascularization and resection of cancer has been well described [1-3], and anterior mediastinal masses, specifically thymomas, encasing bypass grafts have been previously reported [4]. To the best of our knowledge, there have been no reports of adenosquamous carcinoma encasing a coronary artery graft.

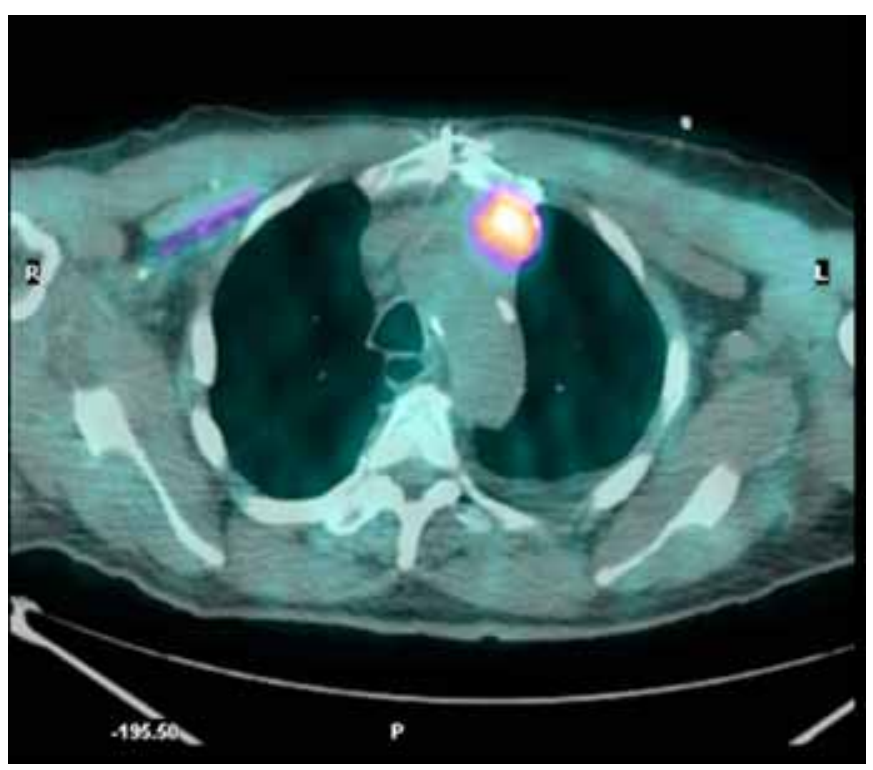

Fig. (4). PET Scan. Axial fused ${ }^{18}$ F-FDG positron emission tomography and computed tomography (PET/CT) scans revealed a $2.0 \mathrm{x}$ $3.5 \mathrm{~cm}$ soft tissue mass with intense FDG uptake in the left aspect of the anterior mediastinum, suspicious for a neoplasm.

Adenosquamous carcinoma of the lung is a rare disease, accounting for $0.4 \%$ to $4.0 \%$ of lung cancers [5]. Although some investigators have reported that the prognosis of adenosquamous carcinoma is the same as for adenocarcinoma [6], other reports indicate a poorer prognosis when compared to adenocarcinoma or squamous cell carcinoma [5, 7-9].

In a review of symptomatology, histology, tumor stage, treatment and prognosis of. adenosquamous carcinoma, patients with Stage III disease - like our patient - had a median survival of 5 months with rapid progression of disease, and only a marginal benefit from chemotherapy or radiotherapy [7].

The recognition that the coronary circulation is almost solely dependent on the LIMA graft and that tumor encasement lead to clinically significant symptomatic ischemia precipitated the need for coronary revasculartization in our patient. Surgical revascularization was deemed unfeasible given his comorbidities and the possibility that the manipulation or traction on the tumor might lead to intraoperative myocardial infarction. Instead we chose percutaneous coronary intervention which was immediately successful. His long-term outcome is unknown.

In summary, when patients present with compromised coronary circulation supplied by the LIMA graft, the usual culprits are at the distal LIMA anastomosis or the progression of native coronary artery disease. In rare instances where the LIMA has a flow-limiting lesion in its middle portion, external compression by a mediastinal mass including the rare adenosquamous carcinoma should be considered. 


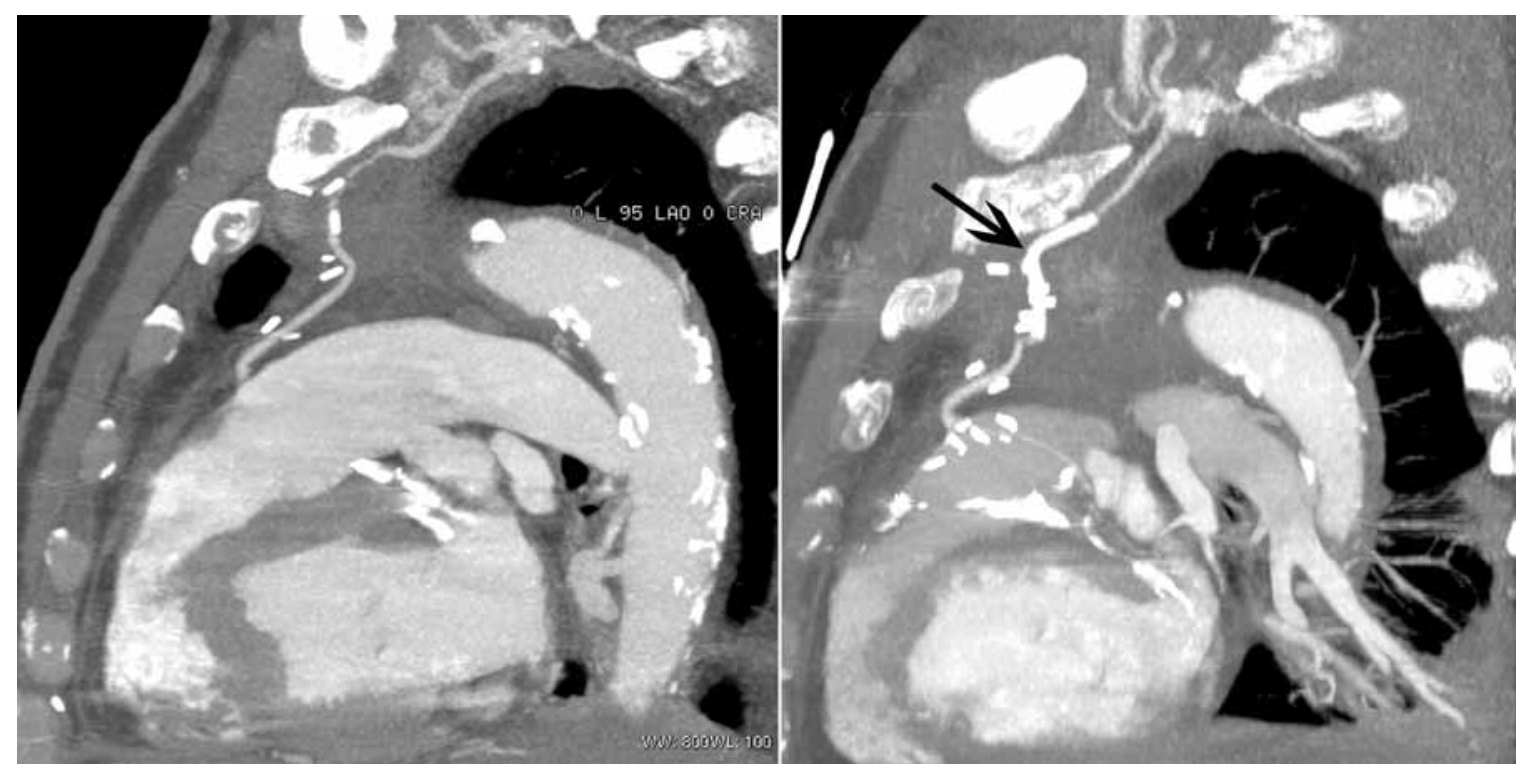

Fig. (5). CT Before and After Stenting. Sagittal maximum intensity projection (MIPS) computed tomography image demonstrating the encasement of the left internal mammary artery bypass graft before and after stenting (arrow).

\section{REFERENCES}

[1] Rosalion A, Woodford NW, Clarke CP, Buxton B. Concomitant coronary revascularization and resection of lung cancer. Aust N Z J Surg 1993; 63(5): 336-40

[2] La Francesca S, Frazier OH, Radovancevic B, De Caro LF, Reul GJ, Cooley DA. Concomitant cardiac and pulmonary operations for lung cancer. Tex Heart Inst J 1995; 22(4): 296-300.

[3] Mirsadraee S, Shah SS, Kumar B, Kaul P. Incidental locally infiltrating malignant thymoma and coronary artery bypass surgery excision should always be considered. J Card Surg 2005; 20: 291-2.

[4] Jaklitsch MT, Byrne JG, Mery C. Thymoma encasing last patent vein graft to the heart. J Thorac Cardiovasc Surg 1999; 118(3): 561-3.
[5] Nakagawa K, Yasumita T, Fukuhara K, Shiono H, Kikui M. Poor prognosis after lung resection for patients with adenosquamous carcinoma of the lung. Ann Thorac Surg 2003; 75: 1740-4.

[6] Hsia JY, Chen CY, Hsu CP, Shai SE, Wang PY. Adenosquamous carcinoma of the lung. Surgical results compared with squamous cell and adenocarcinoma. Scand Cardiovasc J 1999; 33(1): 29-32.

[7] Naunheim KS, Taylor JR, Skosey C, et al. Adenosquamous lung carcinoma: clinical characteristics, treatment, and prognosis. Ann Thorac Surg 1987; 44(5): 462-6.

[8] Takamori S, Noguchi M, Morinaga S, et al. Clinicopathologic characteristics of adenosquamous carcinoma of the lung. Cancer 1991; 67(3): 649-54.

[9] Ruffini E, Rena O, Oliaro A, et al. Lung tumors with mixed histologic pattern: clinico-pathologenic characteristics and prognostic significance. Eur J Cardiothorac Surg 2002; 22(5): 701-7. $\mathrm{nc} / 3.0 /$ ) which permits unrestricted, non-commercial use, distribution and reproduction in any medium, provided the work is properly cited. 